Available online at www.sciencedirect.com

Pergamon

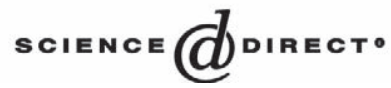

ADDICTIVE BEHAVIORS

Addictive Behaviors 29 (2004) 743-752

Short communication

\title{
Increased intensity of Ecstasy and polydrug usage in the more experienced recreational Ecstasy/MDMA users: A WWW study
}

\author{
Andrew B. Scholey ${ }^{\mathrm{a}, *}$, Andrew C. Parrott ${ }^{\mathrm{b}}$, Tom Buchanan ${ }^{\mathrm{c}}$, \\ Thomas M. Heffernan ${ }^{\mathrm{a}}$, Jonathan Ling ${ }^{\mathrm{d}}$, Jacqui Rodgers ${ }^{\mathrm{e}}$ \\ ${ }^{a}$ Human Cognitive Neuroscience Unit, Psychology Division, Northumbria University, \\ Newcastle-upon-Tyne NE1 8ST, UK \\ ${ }^{\mathrm{b}}$ Department of Psychology, University of Wales Swansea, Swansea SA2 8PP, UK \\ ${ }^{\mathrm{c}}$ Department of Psychology, University of Westminster, London WIB 2UW, UK \\ ${ }^{\mathrm{d}}$ Psychology Section, University of Teesside, Middlesborough TS1 3BA, UK \\ ${ }^{\mathrm{e}}$ Department of Clinical Psychology, University of Newcastle, Newcastle-upon-Tyne NE1 7RU, UK
}

\begin{abstract}
Recreational Ecstasy/MDMA (3,4-methylenedioxymethamphetamine) users often take a variety of psychoactive drugs, but there is little empirical data on how these drug consumption patterns change with greater experience of Ecstasy. The aim of this study was to compare the polydrug usage patterns reported by non-Ecstasy users, novice Ecstasy users, moderate Ecstasy users, and heavy Ecstasy users. In a WWW study of 763 unpaid volunteers, 481 had never taken Ecstasy, whereas 282 reported they had taken it. The Ecstasy users comprised 109 novice users (1-9 occasions), 136 moderate Ecstasy users (10-99 occasions), and 36 heavy Ecstasy users $(+100$ occasions). Each participant also reported their experience with a range of other psychoactive drugs. The Ecstasy users reported significantly greater psychoactive drug usage than the nonEcstasy users. The novice, moderate, and heavy Ecstasy users also differed significantly from each other in the use of cocaine, amphetamine, LSD, and psilocybin mushrooms, but not of alcohol, cannabis, or cigarettes/nicotine. Experienced Ecstasy users also took significantly more MDMA tablets on each occasion, and reported a higher maximum weekly intake. The increased use of Ecstasy is associated with more intensive patterns of Ecstasy/MDMA intake, and the greater use
\end{abstract}

* Corresponding author. Tel.: +44-191-2274468.

E-mail address: a.scholey@unn.ac.uk (A.B. Scholey). 
of illicit CNS stimulants and hallucinogens, but not of alcohol, nicotine, or cannabis. These results are discussed in the context of cross-tolerance and drug predisposition/preference.

(C) 2004 Elsevier Ltd. All rights reserved.

Keywords: Ecstasy; MDMA; Polydrug use; Hallucinogens; Stimulants

\section{Introduction}

MDMA (3,4-methelenedioxymethamphetamine) or Ecstasy is used as an illicit recreational drug by many teenagers and young adults. Around $5 \%$ of schoolchildren in the Netherlands have used it, as have 13\% of British university students (Spruit, 2001; Webb, Ashton, Kelly, \& Kamali, 1996). Its use is strongly associated with the dance club and rave scene, with $59 \%$ of Italian disco clubbers and $81 \%$ of Dutch ravers having experienced it, and $64 \%$ of the Dutch sample stating that they had taken Ecstasy the previous night (Schifano, 2000; Spruit, 2001). In the United States, its availability has also increased dramatically in recent years, so that it is now one of the most frequently used recreational drugs (Chang, 2001; Schensul, 2001). An acute dose of MDMA can lead to intense feelings of euphoria and pleasure, but this is followed over the subsequent days by a "rebound" period of low moods and depression during a period of assumed neurochemical depletion (Curran \& Travill, 1997; Parrott \& Lasky, 1998). The repeated administration of MDMA is neurotoxic in laboratory animals, and there is an increasing body of evidence for serotonergic neuronal injury and functional deficits in humans (McCann, Slate, \& Ricaurte, 1996; Morgan, 2000; Parrott, 2001; Reneman, Booij, Majoie, van den Brink, \& den Heeten, 2001; Ricaurte, Bryan, Strauss, Seiden, \& Schuster, 1985; Ricaurte, Yuan, \& McCann, 2000; Topp, Hando, Dillon, Roche, \& Solowij, 1999). For a more detailed description of the neuropsychopharmacology of MDMA, the following reviews are recommended: Green, Cross, and Goodwin (1995), McCann, Eligulashvili, and Ricaurte (2000), Morgan (2000), Parrott (2000, 2001), and Ricaurte et al. (2000).

There are notably quite marked variations in patterns of Ecstasy/MDMA consumption. Some users take it just a few times, whereas other recreational users take it on hundreds of occasions. Typical doses range from just half a tablet to several tablets together, and there are occasional reports of extremely high doses of 10-25 tablets per session in some very experienced users (Jansen, 1999; Soar et al., in preparation). It has been suggested that this may reflect chronic pharmacodynamic tolerance, although there is a paucity of empirical data on this question (Fox, Parrott, \& Turner, 2001; Parrott, 2001). One of the aims of the current study was therefore to investigate how Ecstasy self-dosing would vary in relation to past experience with the drug. It was hypothesised that the more experienced users would report the most intensive patterns of Ecstasy/MDMA consumption.

It has also been noted that Ecstasy users often take a variety of psychoactive drugs: "Many Ecstasy users are polydrug users who tend to experiment also with hallucinogens, LSD, mushrooms, and cocaine" (Chang, 2001, p. 20). High rates of polydrug use have been found in several studies, with many users taking cannabis (Gouzoulis-Meyfrank et al., 2000; 
Rodgers, 2000), also amphetamine, cocaine, or LSD (Fox et al., 2001; Parrott, Milani, Parmar, \& Turner, 2001; Parrott, Sisk, \& Turner, 2000; Schifano, Di Furia, Forza, Minicuci, $\&$ Bricolo, 1998). Ecstasy users who do not take any other illicit psychoactive drugs seem to be very rare (Rodgers, 2000). Another of the aims of this study was thus to assess the polydrug usage patterns of recreational Ecstasy/MDMA users. It was predicted that Ecstasy users would use more psychoactive drugs than non-Ecstasy users. However, the pattern of polydrug usage reported by the novice Ecstasy users, in comparison with the more experienced Ecstasy users, was less easy to predict. It was unclear whether polydrug use would be a phenomenon of Ecstasy usage per se, or whether the increased use of Ecstasy/ MDMA would be paralleled by an increase in the use of other psychoactive drugs. Additionally, if repeated Ecstasy use results in cross-tolerance to other drugs it might be predicted that increased use of ecstasy would be associated with a concomitant increase in the use of stimulants and hallucinogens but not other classes of drugs. Finally, it should be noted that this study comprised part of a broader WWW investigation into the self-rated memory abilities of recreational drug users and nonusers. The memory questionnaire findings are reported elsewhere (Rodgers et al., 2001, Rodgers et al., 2003); this report is solely concerned with the drug usage patterns.

\section{Materials and methods}

Seven hundred and sixty-three unpaid participants took part in a WWW study (see Rodgers et al., 2001, for details of recruitment and demographics). Of these 463 were female, the modal age group was 21-25 years (32\%), and "some university or college" education was the modal level of educational attainment (31\%). Each volunteer completed two memory self-rating questionnaires (Buchanan et al., in preparation), also the UEL Recreational Drug Use Questionnaire with the response format modified to make it suitable for WWW presentation (Parrott et al., 2001; Rodgers et al., 2001). The question on lifetime usage of Ecstasy/MDMA had five response alternatives: "never in my life," "1-9 occasions," "10-99 occasions," "more than 100 occasions," and "prefer not to answer." All participants chose to answer this question with the majority $(n=481)$ indicating they had never used Ecstasy. The 282 Ecstasy users comprised 109 novice users (1-9 occasions), 136 moderate users (10-99 occasions), and 37 heavy users (+100 occasions).

Further questions covered the lifetime use of cocaine, amphetamine, LSD, opiates, psilocybin (magic) mushrooms, barbiturates/benzodiazepines, opiates, solvents, and anabolic steroids. Cannabis was indicated by self-reported monthly usage, alcohol by units per week, and tobacco/nicotine by cigarettes each day. Each question had five response alternatives similar to those for Ecstasy (see above and Table 1). Further questions covered the normal dose of Ecstasy/MDMA per occasion ( 0 tablets; 12 tablets; 34 tablets; +4 tablets/occasion; or prefer not to answer), and the highest number of Ecstasy/MDMA tablets ever taken in 1 week (0 tablets; 1-2 tablets; 3-9 tablets; + 10 tablets/week; or prefer not to answer). The data were analysed using Pearson chi-squares on SPSS for Windows. Two sets of chi-square 
Table 1

Ecstasy/MDMA users $(n=282)$ and nonusers $(n=481)$ : self-reported use of other psychoactive drugs $(\%$ per group)

\begin{tabular}{|c|c|c|c|c|c|}
\hline Cocaine lifetime use & Never & $1-9$ times & $10-99$ times & +100 times & Chi-square \\
\hline Nonusers of Ecstasy & $90 \%$ & $7 \%$ & $2 \%$ & $1 \%$ & $206.76, d f=3, P<.001$ \\
\hline Ecstasy users & $44 \%$ & $30 \%$ & $23 \%$ & $3 \%$ & \\
\hline Amphetamine lifetime use & Never & 1-9 times & 10-99 times & +100 times & Chi-square \\
\hline Nonusers of Ecstasy & $86 \%$ & $11 \%$ & $2 \%$ & $1 \%$ & $247.81, d f=3, P<.001$ \\
\hline Ecstasy users & $31 \%$ & $35 \%$ & $27 \%$ & $7 \%$ & \\
\hline LSD lifetime use & Never & $1-9$ times & 10-99 times & +100 times & Chi-square \\
\hline Nonusers of Ecstasy & $91 \%$ & $7 \%$ & $2 \%$ & $0 \%$ & 236.11, $d f=3, P<.001$ \\
\hline Ecstasy users & $40 \%$ & $34 \%$ & $23 \%$ & $3 \%$ & \\
\hline Psilocybin mushroom use & Never & 1-9 times & 10-99 times & +100 times & Chi-square \\
\hline Nonusers of Ecstasy & $90 \%$ & $9 \%$ & $1 \%$ & $0 \%$ & $190.50, d f=3, P<.001$ \\
\hline Ecstasy users & $44 \%$ & $42 \%$ & $13 \%$ & $1 \%$ & \\
\hline Cigarette use per day & Nonsmoker & $\begin{array}{l}1-4 \\
\text { cigarettes }\end{array}$ & $\begin{array}{l}5-14 \\
\text { cigarettes }\end{array}$ & $\begin{array}{l}+15 \\
\text { cigarettes }\end{array}$ & Chi-square \\
\hline Nonusers of Ecstasy & $71 \%$ & $8 \%$ & $10 \%$ & $11 \%$ & $54.29, d f=3, P<.001$ \\
\hline Ecstasy users & $47 \%$ & $14 \%$ & $27 \%$ & $12 \%$ & \\
\hline Alcohol use per week & 0 units & $1-9$ units & $10-24$ units & +25 units & Chi-square \\
\hline Nonusers of Ecstasy & $21 \%$ & $46 \%$ & $27 \%$ & $6 \%$ & $13.99, d f=3, P<.01$ \\
\hline Ecstasy users & $21 \%$ & $34 \%$ & $34 \%$ & $11 \%$ & \\
\hline Cannabis use per month & Nonuser & $1-4$ times & $5-20$ times & +20 times & Chi-square \\
\hline Nonusers of Ecstasy & $76 \%$ & $15 \%$ & $5 \%$ & $4 \%$ & $167.70, d f=3, P<.001$ \\
\hline Ecstasy users & $30 \%$ & $31 \%$ & $17 \%$ & $22 \%$ & \\
\hline Barbiturate/Benzodiazepine & Never & 1-9 times & 10-99 times & +100 times & Chi-square \\
\hline Nonusers of Ecstasy & $84 \%$ & $11 \%$ & $4 \%$ & $1 \%$ & 47.94, $d f=3, P<.001$ \\
\hline Ecstasy users & $62 \%$ & $26 \%$ & $11 \%$ & $1 \%$ & \\
\hline Opiate lifetime use & Never & $1-9$ times & $10-99$ times & +100 times & Chi-square \\
\hline Nonusers of Ecstasy & $93 \%$ & $5 \%$ & $1 \%$ & $1 \%$ & $44.59, d f=3, P<.001$ \\
\hline Ecstasy users & $77 \%$ & $16 \%$ & $5 \%$ & $2 \%$ & \\
\hline Solvent lifetime use & Never & $1-9$ times & 10-99 times & +100 times & Chi-square \\
\hline Nonusers of Ecstasy & $90 \%$ & $8 \%$ & $2 \%$ & $0 \%$ & $20.22, d f=3, P<.001$ \\
\hline Ecstasy users & $79 \%$ & $17 \%$ & $3 \%$ & $1 \%$ & \\
\hline Anabolic steroid use & Never & $1-9$ times & 10-99 times & +100 times & Chi-square \\
\hline Nonusers of Ecstasy & $98 \%$ & $1 \%$ & $1 \%$ & $0 \%$ & $7.05, d f=3$, nonsignificant \\
\hline Ecstasy users & $97 \%$ & $2 \%$ & $0 \%$ & $1 \%$ & \\
\hline
\end{tabular}


Table 2

Novice, moderate, and heavy Ecstasy/MDMA users (1-9, 10-99, and +100 lifetime occasions. $N=109,136,37$, respectively): self-reported use of other psychoactive drugs (\% per group)

\begin{tabular}{|c|c|c|c|c|c|}
\hline Cocaine lifetime use & Never & $1-9$ times & $10-99$ times & +100 times & Chi-square \\
\hline Novice Ecstasy users & $56 \%$ & $28 \%$ & $16 \%$ & $0 \%$ & 46.91, $d f=6, P<.001$ \\
\hline Moderate Ecstasy users & $39 \%$ & $33 \%$ & $26 \%$ & $2 \%$ & \\
\hline Heavy Ecstasy users & $19 \%$ & $25 \%$ & $42 \%$ & $17 \%$ & \\
\hline Amphetamine lifetime use & Never & $1-9$ times & 10-99 times & +100 times & Chi-square \\
\hline Novice Ecstasy users & $37 \%$ & $40 \%$ & $17 \%$ & $6 \%$ & $18.78, d f=6, P<.01$ \\
\hline Moderate Ecstasy users & $31 \%$ & $33 \%$ & $31 \%$ & $5 \%$ & \\
\hline Heavy Ecstasy users & $14 \%$ & $29 \%$ & $40 \%$ & $17 \%$ & \\
\hline LSD lifetime use & Never & $1-9$ times & 10-99 times & +100 times & Chi-square \\
\hline Novice Ecstasy users & $49 \%$ & $33 \%$ & $16 \%$ & $2 \%$ & $15.71, d f=6, P<.05$ \\
\hline Moderate Ecstasy users & $37 \%$ & $35 \%$ & $25 \%$ & $3 \%$ & \\
\hline Heavy Ecstasy users & $19 \%$ & $38 \%$ & $35 \%$ & $8 \%$ & \\
\hline Psilocybin mushroom use & Never & $1-9$ times & 10-99 times & +100 times & Chi-square \\
\hline Novice Ecstasy users & $60 \%$ & $30 \%$ & $10 \%$ & $0 \%$ & $27.11, d f=6, P<.001$ \\
\hline Moderate Ecstasy users & $35 \%$ & $51 \%$ & $13 \%$ & $1 \%$ & \\
\hline Heavy Ecstasy users & $30 \%$ & $46 \%$ & $19 \%$ & $5 \%$ & \\
\hline Cigarette use per day & Nonsmoker & $\begin{array}{l}1-4 \\
\text { cigarettes }\end{array}$ & $\begin{array}{l}5-14 \\
\text { cigarettes }\end{array}$ & $\begin{array}{l}+15 \\
\text { cigarettes }\end{array}$ & Chi-square \\
\hline Novice Ecstasy users & $48 \%$ & $17 \%$ & $28 \%$ & $7 \%$ & $7.69, d f=6$, nonsignificant \\
\hline Moderate Ecstasy users & $48 \%$ & $12 \%$ & $27 \%$ & $13 \%$ & \\
\hline Heavy Ecstasy users & $35 \%$ & $19 \%$ & $24 \%$ & $22 \%$ & \\
\hline
\end{tabular}

\begin{tabular}{llllll} 
Alcohol use per week & 0 units & $1-9$ units & $10-24$ units & +25 units & Chi-square \\
\hline Novice Ecstasy users & $18 \%$ & $38 \%$ & $32 \%$ & $12 \%$ & $6.21, d f=6$, nonsignificant \\
Moderate Ecstasy users & $24 \%$ & $33 \%$ & $32 \%$ & $11 \%$ & \\
Heavy Ecstasy users & $13 \%$ & $27 \%$ & $49 \%$ & $11 \%$ &
\end{tabular}

\begin{tabular}{llllll} 
Cannabis use per month & Nonuser & $1-4$ times & $5-20$ times & +20 times & Chi-square \\
\hline Novice Ecstasy users & $32 \%$ & $36 \%$ & $15 \%$ & $17 \%$ & $5.65, d f=6$, nonsignificant \\
Moderate Ecstasy users & $28 \%$ & $30 \%$ & $17 \%$ & $25 \%$ & \\
Heavy Ecstasy users & $32 \%$ & $19 \%$ & $19 \%$ & $30 \%$ &
\end{tabular}

\begin{tabular}{lllccl} 
Barbiturate/Benzodiazepine & Never & $1-9$ times & $10-99$ times & +100 times & Chi-square \\
\hline Novice Ecstasy users & $69 \%$ & $24 \%$ & $4 \%$ & $3 \%$ & $13.88, d f=6, P<.05$ \\
Moderate Ecstasy users & $61 \%$ & $26 \%$ & $12 \%$ & $1 \%$ & \\
Heavy Ecstasy users & $46 \%$ & $32 \%$ & $22 \%$ & $0 \%$ &
\end{tabular}

Opiate lifetime use Never $\quad 1-9$ times $10-99$ times +100 times Chi-square

\begin{tabular}{|c|c|c|c|c|c|}
\hline Novice Ecstasy users & $84 \%$ & $10 \%$ & $2 \%$ & $4 \%$ & $12.36, d f=6,(P=.054)$ \\
\hline
\end{tabular}


Table 2 (continued)

\begin{tabular}{llllll}
\hline Opiate lifetime use & Never & $1-9$ times & $10-99$ times & +100 times & Chi-square \\
\hline Moderate Ecstasy users & $73 \%$ & $18 \%$ & $7 \%$ & $2 \%$ & \\
Heavy Ecstasy users & $67 \%$ & $24 \%$ & $9 \%$ & $0 \%$ & \\
& & & & & \\
Solvent lifetime use & Never & $1-9$ times & $10-99$ times & +100 times & Chi-square \\
\hline Novice Ecstasy users & $81 \%$ & $16 \%$ & $2 \%$ & $1 \%$ & $5.59, d f=6$, nonsignificant \\
Moderate Ecstasy users & $77 \%$ & $19 \%$ & $2 \%$ & $2 \%$ & \\
Heavy Ecstasy users & $73 \%$ & $19 \%$ & $8 \%$ & $0 \%$ & \\
& & & & & \\
Anabolic steroid use & Never & $1-9$ times & $10-99$ times & +100 times & Chi-square \\
\hline Novice Ecstasy users & $98 \%$ & $1 \%$ & $0 \%$ & $1 \%$ & $2.36, d f=4$, nonsignificant \\
Moderate Ecstasy users & $98 \%$ & $2 \%$ & $0 \%$ & $0 \%$ & \\
Heavy Ecstasy users & $97 \%$ & $3 \%$ & $0 \%$ & $0 \%$ & \\
\hline
\end{tabular}

analyses were undertaken. The first was on the Ecstasy users versus nonusers. The second was on the three Ecstasy subgroups.

\section{Results}

The Ecstasy users and nonusers differed significantly in the use of every illicit psychoactive drug apart from anabolic steroids. More of the Ecstasy users than nonusers had taken cannabis, cocaine, amphetamine, LSD, psilocybin mushrooms, opiates, barbiturates/benzodiazepines, and solvents; furthermore, the Ecstasy user group also comprised more of the heavier users (Table 1). The legal psychoactive drugs alcohol and nicotine also showed significant chi-square values, although the drug usage patterns were rather different. Whereas a higher proportion of the Ecstasy users were cigarette smokers, the proportions of light and heavy smokers did not differ between users and nonusers. In contrast, both groups contained similar proportions of alcohol drinkers and nondrinkers, but the Ecstasy group comprised more heavy drinkers (Table 1).

The novice, moderate, and heavy Ecstasy user groups differed significantly in their use of cocaine, amphetamine, LSD, and psilocybin mushrooms (Table 2). For each of these stimulants and hallucinogens, the novice Ecstasy user group had the highest proportion of nonusers and the lowest proportion of moderate or heavy users, whereas the heavy Ecstasy user group had the lowest proportion of stimulant/hallucinogen nonusers, and the highest proportion of heavy stimulant/hallucinogen users (Table 2). The three Ecstasy subgroups also differed in their use of barbiturates/benzodiazepines, with a lower proportion of users amongst the novice Ecstasy group; there was a similar trend for opiates that was statistically borderline (Table 2). The novice, moderate, and heavy Ecstasy user groups did not differ significantly in their use of cannabis, alcohol, cigarettes/tobacco, solvents, or anabolic steroids (Table 2). The fact that the Ecstasy user groups did not differ in terms of their reported usage of this group of substances suggests that the data for the other drugs really do 
Table 3

Normal Ecstasy dose per occasion and maximum number of Ecstasy tablets taken in 1 week, reported by novice, moderate, and heavy Ecstasy/MDMA users (1-9, 10-99, and + 100 lifetime occasions; $N=109$, 136, and 37, respectively)

\begin{tabular}{lcccl}
\hline Normal Ecstasy dose per occasion & $1-2$ tablets & $3-4$ tablets & +4 tablets & Chi-square \\
\hline Novice Ecstasy users & $100 \%$ & $0 \%$ & $0 \%$ & $39.40, d f=4, P<.001$ \\
Moderate Ecstasy users & $84 \%$ & $13 \%$ & $3 \%$ & \\
Heavy Ecstasy users & $62 \%$ & $24 \%$ & $14 \%$ & \\
& & & & \\
Maximum Ecstasy tablets per week & $1-2$ tablets & $3-9$ tablets & +10 tablets & Chi-square \\
\hline Novice Ecstasy users & $91 \%$ & $9 \%$ & $0 \%$ & $169.99, d f=4, P<.001$ \\
Moderate Ecstasy users & $23 \%$ & $68 \%$ & $9 \%$ & \\
Heavy Ecstasy users & $0 \%$ & $65 \%$ & $35 \%$ & \\
\hline
\end{tabular}

reflect elevated usage levels rather than any kind of "yea-saying" bias in the way people are responding to the questionnaire.

The three Ecstasy user subgroups differed significantly in their normal dose of Ecstasy, and the maximum number of Ecstasy tablets ever taken in 1 week (Table 3). Every novice user reported that their normal Ecstasy dose was 1-2 tablets, whereas this "normal dose" was reported by $84 \%$ of the moderate users, and $62 \%$ of the heavy users. The more experienced Ecstasy users often reported higher normal doses of 3-4 tablets or +4 tablets per occasion (Table 3). With reference to the most Ecstasy tablets ever taken in 1 week, 91\% of novice users reported a lifetime maximum of 1-2 tablets/week, whereas this "maximum" was reported by $23 \%$ of moderate users, and $0 \%$ of heavy users. Most of the moderate and heavy Ecstasy users reported a lifetime maximum of 3-9 tablets/week. However, a lifetime maximum of +10 tablets/week was reported by $0 \%$ of novice users, $9 \%$ of moderate users, and $35 \%$ of heavy users (Table 3 ).

\section{Discussion}

More Ecstasy users than nonusers took cannabis, amphetamine, cocaine, LSD, psilocybin mushrooms, solvents, and opiates, while significantly more of them were cigarette smokers and/or heavy alcohol drinkers (Table 1). This confirms previous reports of polydrug use amongst recreational Ecstasy users. Gouzoulis-Meyfrank et al. (2000) and Rodgers (2000) noted that many Ecstasy users also took cannabis. Chang (2001) commented that Ecstasy users often took a variety of psychoactive drugs, including stimulants and hallucinogens. Fox et al. (2001) found that significantly more Ecstasy users took amphetamine, cocaine, or LSD, in comparison with cannabis-user controls. Other studies have similarly noted that multiple psychoactive drug use is a typical characteristic of Ecstasy users (Heffernan, Ling, \& Scholey, 2001; Morgan, 1999; Parrott et al., 2000, 2001; Pedersen \& Skrondal, 1999; Schifano, 2000; Topp et al., 1999). These findings are consistent with the notion of thresholds, that drug escalation follows a characteristic progression, from legal drugs, to cannabis, then other illicit 
drugs. Pedersen and Skrondal (1999, p. 1695) noted in their Norwegian survey that "Ecstasy is used by adolescents who use other legal and illegal substances in a polydrug-use pattern." They found that the recreational use of Ecstasy/MDMA was typically preceded by alcohol, nicotine, cannabis, and amphetamine, in that order.

The novice, moderate, and heavy Ecstasy users showed significantly different patterns of stimulant and hallucinogen use, whereas the use of cannabis, alcohol, and nicotine was similar across subgroups (Table 2). Thus, whereas $44 \%$ of the novice Ecstasy users had tried cocaine, this percentage increased to $61 \%$ of the moderate Ecstasy users and $81 \%$ of the heavy Ecstasy users (Table 2). Furthermore, the percentage reporting the use of cocaine on 10 or more occasions increased from 3\% of the non Ecstasy users to $16 \%$ of the novice Ecstasy users, $28 \%$ of the moderate Ecstasy users, and $59 \%$ of the heavy Ecstasy users (Tables 1 and 2). Similar findings were apparent with amphetamine, LSD, and psilocybin mushrooms; in each case, the increasing use of Ecstasy was associated with more widespread and heavier use of these other stimulants/hallucinogens. In contrast, the use of cannabis, alcohol, and nicotine remained similar across the Ecstasy subgroups (Table 2). Various explanations for these differential drug usage patterns may be proposed. The simplest is that it reflects a preference for, or even predisposition toward, stimulant/hallucinogenic types of drug, with acute MDMA generating a mixture of stimulatory and hallucinogenic experiences (Davison and Parrott, 1997; Solowij, 1993). However, there are alternative explanations. Some regular Ecstasy state that their regular drug use has become repetitive, and they need other psychoactive drugs and/ or drug cocktails to generate positive on-drug experiences. Related to this, many regular users describe pharmacodynamic tolerance to MDMA/Ecstasy, complaining that their acute drug reaction has weakened with repeated usage (Merrill, 1996; Parrott, 2001; Peroutka, Newman, \& Harris, 1988; see below). The increasing use of other stimulant and hallucinogenic drug by regular Ecstasy users may therefore reflect an attempt to maintain a "positive" on-drug reaction in the face of increasing tolerance to MDMA. If confirmed this would suggest crosstolerance between MDMA and other stimulants/hallucinogens (although it should be noted that we cannot say whether Ecstasy use preceded the use of other stimulants/hallucinogens from these data). This phenomenon does not seem to have been previously described, although it would certainly be neuropharmacologically predicted. It should, however, be emphasized that the current cross-sectional data are insufficient to distinguish between these different explanations; prospective data are needed.

One obvious question to ask is whether heavier users of Ecstasy tend to be older: logically, those using the drug for longer periods should report higher lifetime totals of use, as they would have had more time to consume more drugs. For the 282 Ecstasy users, a KruskallWallis test indicated that age group did not differ significantly across drug use categories $\left[\chi^{2}(1)=0.001, n=282, P=.974\right]$. The median age group was $21-25$ years old for low, medium, and heavy user groups. However, estimated lifetime total use was significantly associated with the time since people first took Ecstasy $\left(r_{\mathrm{s}}=.252, n=282, P<.0005\right)$. This relationship persists when age is controlled for in the analysis by means of partial correlations $(r=.290, d f=279, P<.0005)$.

Empirical evidence for pharmacodynamic tolerance to MDMA was, however, evident in the Ecstasy self-administration findings (Table 3). The dose of Ecstasy normally taken and the 
maximum number of Ecstasy tablets taken in 1 week both increased significantly in parallel with greater Ecstasy usage (Table 3). These findings parallel those of Fox et al. (2001), who noted that their low users tended to take a smaller average/normal dose than their high user group, with the medium user group being intermediate $(1.8,2.2$, and 3.7 tablets for the low, medium, and heavy user groups, respectively, although the group difference was borderline in significance: $P=10$, two-tailed). There was, however, a significant relationship for the largest number of tablets ever taken on one occasion, with 3.6, 5.1, and 10.9 tablets for the novice, moderate, and heavy user groups, respectively ( $P=.002$; Fox et al., 2001). The current data (Table 3) and those of Fox et al. are suggestive of pharmacodynamic tolerance, although prospective data are needed to show how self-dosing patterns change over time. Finally the three Ecstasy subgroups reported significantly different patterns of barbiturates/benzodiazepine use, while the equivalent data for opiates was statistically borderline (Table 2). Ecstasy users typically report anhedonia and depression in the days following Ecstasy (Curran \& Travill, 1997; Parrott \& Lasky, 1998), and many regular users state that they take sedativerelaxants such as cannabis, diazepam, or opiates to relieve these unpleasant rebound effects. The greater use of some types of sedative-relaxant drugs by heavier Ecstasy users may possibly reflect this, although there are limited empirical data on this phenomenon (Pedersen \& Skrondal, 1999). Again, prospective studies are needed to investigate how the regular use of Ecstasy may affect the frequency and/or intensity of other illicit psychoactive drug use.

\section{References}

Buchanan, T., Ali, T., Heffernan, T. M., Ling, J., Parrott, A., Rodgers, J., \& Scholey, A. B. (Submitted). Nonequivalence of online and paper- and -pencil psychological tests: The case of the Prospective Memory Questionnaire.

Chang, L. (2001). Neuroimaging studies in chronic effects of MDMA/Ecstasy use. NIDA Scientific Conference on MDMA/Ecstasy: Advances, challenges, and future directions, National Institute on Drug Abuse, Bethesda, MD, USA, July 2001 (p. 20), Program abstract.

Curran, H. V., \& Travill, R. A. (1997). Mood and cognitive effects of 3,4-methylenedioxymethamphetamine (MDMA, "ecstasy"): Weekend "high" followed by mid-week "low". Addiction, 92, 821-831.

Davison, D., \& Parrott, A. C. (1997). Ecstasy in recreational users: Self-reported psychological and physiological effects. Human Psychopharmacology Clinical and Experimental, 12, 91-97.

Fox, H., Parrott, A. C., \& Turner, J. J. D. (2001). Ecstasy/MDMA related cognitive deficits: A function of dosage rather than awareness of problems. Journal of Psychopharmacology, 15, 273-281.

Gouzoulis-Meyfrank, E., Daumann, J., Tuchtenhagen, F., Pelz, S., Becker, S., Kunert, H. J., Fimm, B., \& Sass, H. (2000). Impaired cognitive performance in drug free users of recreational ecstasy (MDMA). Journal of Neurology, Neurosurgery and Psychiatry, 68, 719-725.

Green, A. R., Cross, A. J., \& Goodwin, G. M. (1995). Review of the pharmacology and clinical pharmacology of 3,4-methylenedioxymethamphetamine (MDMA or Ecstasy). Psychopharmacology, 119, 247-260.

Heffernan, T. M., Ling, J., \& Scholey, A. B. (2001). Subjective ratings of prospective memory deficits in MDMA ('ecstasy') users. Human Psychopharmacology Clinical and Experimental, 16, 339-344.

Jansen, K. L. R. (1999). Ecstasy (MDMA) dependence. Drug and Alcohol Dependence, 53, $121-124$.

McCann, U. D., Eligulashvili, V., \& Ricaurte, G. A. (2000). ( \pm ) 3,4-Methylenedioxymethamphetamine ('Ecstasy')-induced serotonin neurotoxicity: Clinical studies. Neuropsychobiology, 42, 11-16.

McCann, U. D., Slate, S. O., \& Ricaurte, G. A. (1996). Adverse reactions with 3,4-methylenedioxymethamphetamine (MDMA; "Ecstasy”). Drug Safety, 15, 107-115. 
Merrill, J. (1996). Ecstasy and neurodegeneration. British Medical Journal, 313, 423.

Morgan, M. J. (1999). Memory deficits associated with recreational use of "ecstasy" (MDMA). Psychopharmacology, 141, 30-36.

Morgan, M. J. (2000). Ecstasy (MDMA): A review of its possible persistent psychological effects. Psychopharmacology, 152, 230-248.

Parrott, A. C. (2000). Human research on MDMA (3,4-methylenedioxymethamphetamine) neurotoxicity: Cognitive an behavioral indices of change. Neuropsychobiology, 42, 17-24.

Parrott, A. C. (2001). Human psychopharmacology of Ecstasy (MDMA): A review of 15 years of empirical research. Human Psychopharmacology Clinical and Experimental, 16, 557-577.

Parrott, A. C., \& Lasky, J. (1998). Ecstasy (MDMA) effects upon mood and cognition; before, during, and after a Saturday night dance. Psychopharmacology, 139, 261-268.

Parrott, A. C., Milani, R., Parmar, R., \& Turner, J. J. D. (2001). Ecstasy polydrug users and other recreational drug users in Britain and Italy: Psychiatric symptoms and psychobiological problems. Psychopharmacology, 159, $77-82$.

Parrott, A. C., Sisk, E., \& Turner, J. (2000). Psychobiological problems in heavy 'ecstasy' (MDMA) polydrug users. Drug and Alcohol Dependence, 60, 105-110.

Pedersen, W., \& Skrondal, A. (1999). Ecstasy and new patterns of drug use: A normal population study. Addiction, 94, 1695-1706.

Peroutka, S. J., Newman, H., \& Harris, H. (1988). Subjective effects of 3,4-methylenedioxymethamphetamine in recreational users. Neuropsychopharmacology, 1, 273-277.

Reneman, L., Booij, J., Majoie, C. B. L., van den Brink, W., \& den Heeten, G. J. (2001). Investigating the potential neurotoxicity of Ecstasy (MDMA): An imaging approach. Human Psychopharmacology Clinical and Experimental, 16, 579-588.

Ricaurte, G. A., Bryan, G., Strauss, L., Seiden, L. S., \& Schuster, C. R. (1985). Hallucinogenic amphetamine selectively destroys brain serotonin nerve terminals. Science, 229, 986-988.

Ricaurte, G. A., Yuan, J., \& McCann, U. D. (2000). ( \pm ) 3,4-Methylenedioxymethamphetamine (MDMA, "Ecstasy")-induced serotonin neurotoxicity: Studies in animals. Neuropsychobiology, 42, 5-10.

Rodgers, J. (2000). Cognitive performance amongst recreational users of "ecstasy". Psychopharmacology, 151, $19-24$.

Rodgers, J., Buchanan, T., Scholey, A. B., Heffernan, T. M., Ling, J., \& Parrott, A. (2001). Differential effects of ecstasy and cannabis on self reports of memory ability: A web-based study. Human Psychopharmacology Clinical and Experimental, 16, 619-625.

Rodgers, J., Buchanan, T., Scholey, A. B., Heffernan, T. M., Ling, J., \& Parrott, A. C. (2003). Patterns of drug use and the influence of gender on self-reports of memory ability in ecstasy users: A web-based study. Journal of Psychopharmacology, 17, 389-397.

Schensul, J. J. (2001). The diffusion of MDMA use among urban youth in Hartford, Connecticut. NIDA Scientific Conference on 'MDMA/Ecstasy: Advances, challenges, and future directions,' National Institute on Drug Abuse, Bethesda, MD, USA, July 2001 (p. 38), Program abstract.

Schifano, F. (2000). Potential human neurotoxicity of MDMA ('Ecstasy'): Subjective self-reports, evidence form an Italian drug addiction centre and clinical case studies. Neuropsychobiology, 42, 25-33.

Schifano, F., Di Furia, L., Forza, G., Minicuci, N., \& Bricolo, R. (1998). MDMA ('ecstasy') consumption in the context of polydrug abuse: A report on 150 patients. Drug and Alcohol Dependence, 52, 85-90.

Solowij, N. (1993). Ecstasy (3,4-methylenedioxymethamphetamine). Current Opinion in Psychiatry, 6, 411-415.

Spruit, I. P. (2001). Monitoring synthetic drug markets, trends and public health. Substance Use and Misuse, 36, $23-47$.

Topp, L., Hando, J., Dillon, P., Roche, A., \& Solowij, N. (1999). Ecstasy use in Australia: Patterns of use and associated harm. Drug and Alcohol Dependence, 55, 105-115.

Webb, E., Ashton, C. H., Kelly, P., \& Kamali, F. (1996). Alcohol and drug use in UK university students. Lancet, 348, 922-925. 